\title{
Introduction of Advanced Practice Physiotherapy in Dutch Primary Care is a Search for Possibilities, Added Value, and Mutual Trust; A Qualitative Study Among Advanced Practice Physiotherapist and General Practitioners.
}

\section{Sylvia Pellekooren ( $\nabla$ s.pellekooren@vu.nl)}

Department of Health Sciences, Faculty of Science, Vrije Universiteit, Amsterdam

\section{Marianne Donker}

Department of Health Sciences, Faculty of Science, Vrije Universiteit, Amsterdam

\section{Eddy Reijnders}

Huisartsopleiding VUmc, Amsterdam UMC, Location VUmc

\section{Lamyae Boutalab Msc}

Department of Health Sciences, Faculty of Science, Vrije Universiteit, Amsterdam

\section{Raymond Ostelo}

Department of Health Sciences, Faculty of Science, Vrije Universiteit, Amsterdam

\section{Maurits Tulder}

Department of Human Movement Sciences, Faculty of Behavioral \& Movement Sciences, Vrije Universiteit, Amsterdam

\section{Annelies Pool-Goudzwaard}

Department of Human Movement Sciences, Faculty of Behavioral \& Movement Sciences, Vrije Universiteit, Amsterdam

\section{Research Article}

Keywords: Advanced Practice Physiotherapy, Extended Scope Specialist, Extended Scope Practitioners, Primary health care, Physiotherapy, Musculoskeletal Complaints, General Practitioner Care

Posted Date: January 27th, 2022

DOI: https://doi.org/10.21203/rs.3.rs-1259458/v1

License: (-) (i) This work is licensed under a Creative Commons Attribution 4.0 International License. Read Full License 


\section{Abstract}

Background: Despite the increasing deployment and added value of Advanced Practitioner in Physiotherapy (APP) in musculoskeletal care internationally, APP is not widely accepted in Dutch primary care yet. This may be due to constraints in the implementation of APP within the Dutch health care system. The aim of this study was to explore experiences and perceptions of APP and General Practitioners (GP) in implementing APP in Dutch primary care.

Methods: This was an explorative and interpretive qualitative study among 13 APPs and 3 GPs that were in various stages of implementing an APP care model. Semi-structured interviews were conducted from January to March 2021. The topic list was based on existing literature, personal input of researchers, and the Constellation Approach framework. Data were analysed using a thematic inductive approach.

Results: Four main themes emerged from the data; 1) The start-up of an APP practice requires trust and clear added value for the GP, 2) Starting APP must be strongly supported by GP, 3) Positioning of APP is still unclear, and 4) Ownership of patients with musculoskeletal complaints. These four themes put forward perceived difficulties in gaining trust, lack of clarity regarding the added value of APP, ambiguity of the APP's professional profile and positioning, lack of reimbursement structure, and APP's struggle in seeking balance with current care.

Conclusion: This study shows that the implementation of an APP model of care is challenging. The deployment of APP does not sufficiently align with the core values of GPs, and GPs seem reluctant to handover some control over patient care to APPs. APP does not appear to have ownership of the implementation, given its strong dependence on the practice, values and needs of the GP.

Trial registration: Ethical approval is obtained from the Medical Ethics Committee of the VU University Medical Centre in Amsterdam; reference number 2020.17. All participants were asked written informed consent before participating in this study.

\section{Introduction}

Throughout the years health care utilization is increasing, and is expected to increase even further, due to health care innovations and an aging population [1]. Just like any other health care system in the world, the Dutch health care system has to deal with this increasing demand for health care, leading to a growing workload for healthcare workers. Especially Dutch general practitioners (GPs), who are not only taking over tasks from secondary health care facilities, but who are also facing a declining number of working colleagues [2], experience that their workload is increasing considerably [3].

One solution for decreasing the workload of GPs is the deployment of additional care givers. For example, nurse practitioners and physician assistants have taken over some of the tasks of GPs in the treatment of patients with chronic conditions, such as diabetes [4] and depression [5-7]. Following these examples, there have been various initiatives worldwide to relieve GPs in the care for the significant group of patients with 
musculoskeletal conditions seeking treatment, including an Advanced Practitioner in Physiotherapy (APP), also referred to as Extended Scope Practitioner (ESP) [8, 9].

APP operates at an advanced level of practice and performs tasks that are traditionally performed by other medical professionals, such as setting and communicating diagnoses, triaging for surgery or surgical opinion, ordering diagnostic imaging or laboratory tests, and prescribing/injecting medications $[9,10]$. A recently published study showed that reallocating tasks to APP contributes to accessibility of care with comparable health effects, diagnostic accuracy, and patient satisfaction [9]. In addition, APP model of care might result in lower health care costs compared to usual care [11]. Based on these international findings, APP seem to be an appropriate alternative in the treatment of patients with musculoskeletal conditions, and may help reducing the workload of GPs.

In response to these international developments, APP was introduced in the Netherlands a few years ago as Extended Scope Specialist. Despite the promising international findings, the deployment of APP in Dutch primary care is not widely accepted yet. This may be due to barriers in the implementation of such innovations within the Dutch health care system, which is characterized by a strong position of the GP [12, 13]. This strong position is due to the fact that Dutch GPs are gatekeepers for secondary care and all inhabitants are registered with their own GP. This results in a long-term relationship of trust, characterised by a strong focus on shared decision-making, and high continuity of care [13].

Several qualitative studies [14-18] have explored the barriers and facilitators in the implementation of APP in secondary health care settings, and have shown that knowledge, skills, availability of APP, motivation and experience have a large impact on successful implementation. Although these studies are of great value in improving the implementation of APP, their outcomes may not be applicable for the Dutch primary care setting. As these studies focused on the implementation of APP in secondary care facilities in other health care systems, barriers and facilitators specific to the Dutch primary care setting may not be identified. Moreover, findings of these studies were mainly based on experiences of APP, hereby overlooking the GP perspective. Therefore, the aim of this study was to explore experiences and perceptions of Dutch APPs and GPs in implementing APP in Dutch primary care. Although the term Extended Scope Specialist is used in the Netherlands, the acronym APP is used throughout the manuscript, hereby following the term used in recent publications [8, 9-11].

\section{Method}

\section{Design}

This was an explorative and interpretive qualitative study among Dutch APPs and GPs who were in various stages of implementing a musculoskeletal APP care model in a primary care setting. Semi-structured interviews were conducted from January to March 2021.

\section{Framework}

The framework used to enrich the interview guide was the Constellation Approach [19], which was developed to analyse transitions in complex systems. The constellation approach assumes that complex societal 
systems, such as the Dutch health care system, consists of several subsystems, so called constellations. These constellations interact with, and adapt to, each other, as well as their systems environment. Each constellation consists of three elements, namely structure, culture, and practice. Structure refers to the physical, economic, financial, legal, organizational, and power structures that influence the behaviour of actors within a constellation. Practice concerns the actual actions undertaken within a constellation, such as interactions between health care professionals and patients or professionals and management. Culture is the set of values, perceptions and interpretations of actors within the constellation (e.g., patients, physicians, health care providers and insurance companies). A constellation may change due to a variety of influences originating from within the organisation but can also by demand- or supply-driven. When implementing APP in the Netherlands, the question is whether the health care structure, the beliefs of those involved, and the daily practice of musculoskeletal care are open to the introduction of APP.

\section{Participants}

APPs were approached through the researchers' existing network, the alumni association, and the professional association. GPs were approached through the researchers' existing network and regional GP associations. In order to achieve maximum variation and collect meaningful experiences and perceptions, APPs were selected based on stage of implementation and personal and practice characteristics. GPs were selected on the basis of convenience sampling, as this proved to be a difficult group to recruit.

\section{Data collection and Data analysis}

The topic list was based on the available knowledge from the literature [14-18], enriched with elements of the constellation approach (i.e., culture, structure and practice characteristics) [19], and the personal input of the researchers (SP, ER, AP). The topic list included the following topics; reasons for starting a collaboration, extent of implementation and activities of APPs, training of APPs, awareness and need for an APP, support from the professional association, barriers and facilitators in the collaboration, alignment with the core values of Dutch general practice, and opportunities and future prospects for APPs. A full overview of the topic lists can be found in Additional file 1.

The duration of the interviews was around 60 minutes, except for one interview of 30 minutes, and were conducted through an online video call. Interviews were audio recorded and fieldnotes were taken. A pseudonymized verbatim transcription of the audio recordings was obtained. Summaries (i.e., member checks) were sent to participants to provide the opportunity to comment and adjust the summary of their interview [20]. Data were thematically analysed by means of an inductive approach [21]. Two researchers (SP and LB) familiarised themselves with the data by reading and rereading the transcripts, and subsequently independently selected relevant fragments from three interviews by assigning open codes. These codes were discussed and agreed upon with a third researcher (MD). After coding the first three interviews, a set of open codes was composed with which the remaining interviews were coded. Within this set, it was possible to add new codes. New codes were discussed within the research team and the set of codes was adjusted, if necessary. Next, the codes were compared and grouped according to main- and subthemes. After nine interviews, no new themes were found and data saturation was achieved. Valuable quotes were selected during the analysis and then discussed and interpreted among researchers (SP, MD). 
Two native English speakers translated the quotes from Dutch to English. All analyses were conducted in MAXQDA (version 2020).

\section{Ethical considerations}

All participants have given informed consent before participating in this study. Ethical approval was obtained from the Medical Ethics Committee of the VU University Medical Centre in Amsterdam; reference number 2020.17.

\section{Results}

After recruitment twelve APPs and four GPs were included, of which one GP decided not to participate due to a busy schedule. APPs included differed in personal characteristics and specific working conditions, such as way of reimbursement and organisational embedment. Seven of the thirteen APPs had a collaboration with a GP, of which two worked under supervision of the GP and five worked independently. More details on the participants are presented in Table 1. 
Table 1

CHARACTERISTICS OF PARTICIPANTS

\begin{tabular}{|c|c|c|c|c|c|c|c|}
\hline Respondent & Gender & Age & $\begin{array}{l}\text { Years of } \\
\text { work } \\
\text { experience } \\
\text { as PT }\end{array}$ & $\begin{array}{l}\text { Years after } \\
\text { graduating } \\
\text { APP }\end{array}$ & $\begin{array}{l}\text { Currently } \\
\text { practicing } \\
\text { as APP }\end{array}$ & \multicolumn{2}{|c|}{$\begin{array}{l}\text { APP working under } \\
\text { supervision }\end{array}$} \\
\hline APP $1^{*}$ & Female & $\begin{array}{l}> \\
50\end{array}$ & $>25$ & $>2$ & Yes & \multicolumn{2}{|l|}{$+\star \star *$} \\
\hline APP $2^{\star}$ & Female & $\begin{array}{l}> \\
50\end{array}$ & $>30$ & $>2$ & No & \multicolumn{2}{|l|}{$+\star \star \star$} \\
\hline APP $3^{*}$ & Female & $\begin{array}{l}> \\
60\end{array}$ & $>30$ & $>2$ & Yes & \multicolumn{2}{|l|}{+} \\
\hline APP $4^{\star}$ & Male & $\begin{array}{l}> \\
50\end{array}$ & $>20$ & $>2$ & Yes & \multicolumn{2}{|l|}{+} \\
\hline APP 5 & Female & $\begin{array}{l}> \\
35\end{array}$ & $>10$ & $<2$ & Yes & \multicolumn{2}{|l|}{$-* \star *$} \\
\hline APP 6* & Female & $\begin{array}{l}> \\
45\end{array}$ & $>20$ & $<2$ & Yes & \multicolumn{2}{|l|}{$-* \star \star$} \\
\hline APP 7* & Male & $\begin{array}{l}> \\
55\end{array}$ & $>35$ & $>6$ & Yes & \multicolumn{2}{|l|}{+} \\
\hline APP 8* & Female & $\begin{array}{l}> \\
40\end{array}$ & $>20$ & $>2$ & Yes & \multicolumn{2}{|l|}{+} \\
\hline APP 9* & Female & $\begin{array}{l}> \\
40\end{array}$ & $>15$ & $>4$ & No & \multicolumn{2}{|l|}{$\mathrm{Na}$} \\
\hline APP 10* & Male & $\begin{array}{l}> \\
30\end{array}$ & $>10$ & $>2$ & No & \multicolumn{2}{|l|}{$\mathrm{Na}$} \\
\hline APP 11* & Male & $\begin{array}{l}> \\
40\end{array}$ & $>15$ & $<2$ & No & \multicolumn{2}{|l|}{$\mathrm{Na}$} \\
\hline APP 12* & Male & $\begin{array}{l}> \\
40\end{array}$ & $>20$ & $<2$ & No & \multicolumn{2}{|l|}{$\mathrm{Na}$} \\
\hline Respondent & Gender & Age & $\begin{array}{l}\text { Years of } \\
\text { work } \\
\text { experience }\end{array}$ & $\begin{array}{l}\text { Practice } \\
\text { composition }\end{array}$ & $\begin{array}{l}\text { Number } \\
\text { of } \\
\text { patients } \\
\text { registered } \\
\text { to GP } \\
\text { practice }\end{array}$ & $\begin{array}{l}\text { Number of } \\
\text { collaborating } \\
\text { APP }\end{array}$ & $\begin{array}{l}\text { APP } \\
\text { working } \\
\text { under } \\
\text { supervision }\end{array}$ \\
\hline GP1* & Male & $>55$ & 25 & $\begin{array}{l}1 \mathrm{GP}, 1 \\
\text { permanent } \\
\text { alternate }\end{array}$ & 2200 & 2 & + \\
\hline GP2* & Female & $>40$ & 13 & $2 \mathrm{GP}$ & 2900 & 1 & - \\
\hline GP3* & Female & $>50$ & 21 & $\begin{array}{l}1 \text { GP, } 1 \\
\text { HIDHA, } 1 \\
\text { HAIOS }\end{array}$ & 3000 & 1 & + \\
\hline
\end{tabular}




\begin{tabular}{|c|c|c|c|c|c|c|}
\hline Respondent & Gender & Age & $\begin{array}{l}\text { Years of } \\
\text { work } \\
\text { experience } \\
\text { as PT }\end{array}$ & $\begin{array}{l}\text { Years after } \\
\text { graduating } \\
\text { APP }\end{array}$ & $\begin{array}{l}\text { Currently } \\
\text { practicing } \\
\text { as APP }\end{array}$ & $\begin{array}{l}\text { APP working under } \\
\text { supervision }\end{array}$ \\
\hline
\end{tabular}

Four main themes derived from the data; the start-up of an APP practice requires trust and clear added value for the GP (1), Starting APP must be strongly supported by GP (2), positioning of APP is still unclear (3), and tension regarding passing on ownership of patients with musculoskeletal complaints (4). Details on the derived subthemes and axial codes are shown in the code tree, which is presented in Table 2. 
Table 2

CODE TREE

$\begin{array}{lll}\text { Themes } & \text { Subthemes } & \text { Axial codes }\end{array}$

The start-up of an APP practice

GP needs trust in APP in

requires trust and clear added value order to gain confidence

for the GP

A clear added value of APP

for GP is a prerequisite

Starting APP must be strongly

supported by GP

Novice APP needs formal support of the GP in order

APP cannot refer to secondary to start care on their own

Limited availability of patient information

Triaging patients lacks criteria

GP and APP struggle with who is in charge of the care pathway

Gaining self-confidence Insecurity during delivering care

APP is dependent of support of GP

Insecurity during team interaction

More flying hours increases self confidence

APP needs practical APP and GP need to invest in support of multiple GP to realise practice common language

Workplace APP is under discussion

APP, GP and health care insurers want to scale up

Establishment of proper reimbursement is crucial

Positioning of APP is still unclear

APP professional profile requires clarification
Competencies and attainment levels are poorly crystalized

Preference for type of employment and final responsibility differ

Experienced tension between GP standards and working method APP 


\begin{tabular}{|c|c|c|}
\hline Themes & Subthemes & Axial codes \\
\hline & $\begin{array}{l}\text { More guidance from trade } \\
\text { organisation is desirable }\end{array}$ & $\begin{array}{l}\text { APP desires more backing from } \\
\text { trade organisation }\end{array}$ \\
\hline & & $\begin{array}{l}\text { Trade organisation needs to be a } \\
\text { driving force towards stakeholders }\end{array}$ \\
\hline & $\begin{array}{l}\text { APP experience limited } \\
\text { added value of training } \\
\text { attended }\end{array}$ & $\begin{array}{l}\text { Work experience influences added } \\
\text { value of training }\end{array}$ \\
\hline & & $\begin{array}{l}\text { Curriculum needs more in-depth } \\
\text { and practical training }\end{array}$ \\
\hline $\begin{array}{l}\text { Tension regarding passing on } \\
\text { ownership of patients with } \\
\text { musculoskeletal complaints }\end{array}$ & $\begin{array}{l}\text { No place for APP among } \\
\text { physiotherapy yet }\end{array}$ & $\begin{array}{l}\text { Gaining trust among } \\
\text { physiotherapist s needed to } \\
\text { collaborate }\end{array}$ \\
\hline & & Controversy on positioning APP \\
\hline & $\begin{array}{l}\text { Find balance in taking over } \\
\text { GP tasks and safeguarding } \\
\text { core values }\end{array}$ & $\begin{array}{l}\text { Deployment of APP jeopardises } \\
\text { patient centred care }\end{array}$ \\
\hline & & $\begin{array}{l}\text { Ensuring independent delivery of } \\
\text { care seems unfeasible ideal }\end{array}$ \\
\hline & & $\begin{array}{l}\text { GP must be able to maintain the } \\
\text { delivery of general medical care at } \\
\text { a qualified level }\end{array}$ \\
\hline
\end{tabular}

\section{The start-up of an APP practice requires trust and clear added value for the GP}

GP needs trust in APP in order to gain confidence

The GP needs trust in both competencies and motivations of APP to gain confidence in the collaboration. APPs who do not have a pre-existing relationship of trust have difficulty connecting with GPs and gaining their trust.

The most important factor is trust. Trust that those who are doing the project, APP X and APP Y, are competent in the matter. That they are also prepared to behave in this way, and not say, this is a disguised way of bringing in more clients at the end of the day, so that is the most important thing, I think. [GP 1]

A clear added value of APP for GP is a prerequisite

Many GPs are still unfamiliar with APP and what the profession entails. GPs have difficulty seeing the added value in quality of care of APPs over physiotherapists, and it is not yet sufficiently clear to GPs what the deployment of APP will bring them personally and professionally. It is up to the individual starting APP to prove their added value, and to convince GPs to transfer tasks without calling into question GPs competences. 
Because of course there are so many different therapists with all kinds of functions. It has to be very clear what exactly the added value is for us to refer a patient to an APP instead of a 'regular' physio. [GP 2]

\section{Starting APP must be strongly supported by GP}

Novice APP needs formal support of the GP in order to start

The vast majority of APP indicate that the start-up of an APP practice is a long process involving many steps. Support of the GP is essential for referring to secondary care, eliciting enough patient information for setting out the care pathway properly, and setting up referral streams. This is mainly caused by legislative issues such as General Data Protection Regulation and doctor-patient confidentiality. GPs feel responsible for their patients and need trust to hand over tasks to APP. This trust can grow by working together. Hence, some GPs initially opt for joint consultation or deploy APP under supervision and set out the care pathway themselves. APPs who do set out the care pathway themselves indicate that, despite agreements made, they sometimes have trouble staying in charge of the treatment plan.

I should like it to be under my supervision because I think that in this way I can offer an extra service to my patients, a broader selection of diagnostic skills and I don't throw this [treatment responsibility] out. So, for as far as this goes, I want them [patients] to go to it [APP], and then they often return to me, and we discuss what the proposed treatment plan is. In this way I don't let go of them. [GP1]

Gaining self-confidence APP is dependent of support of GP

All practicing APPs sometimes feel insecure and vulnerable in having primary responsibility for patients' wellbeing, especially when complaints may not seem to be related to the musculoskeletal domain. Consultation with fellow APPs or the authorizing GP helps to reduce this uncertainty. Practicing APPs have felt uncertain in reporting to the GP and felt that they were not allowed to make mistakes in this initial phase where they still have to prove themselves. Self-confidence grows by receiving positive feedback from the GP and gaining more work experience.

It would be a death blow of course, everyone makes mistakes, but it would mean the end of everything if we have a lot of misdiagnoses in the initial phase. Then, immediately, seeds of doubt are sown, and of course, we can't have that. [APP 4]

APP needs practical support of multiple GP to realise practice

Some APPs and GPs indicate that a uniform way of working, and communication is important to ensure high quality of care and perform joint consultations to achieve this. All APPs and GPs preferred a workplace within a health centre where several GPs work, as APPs will be embedded in the GP practice and short lines of communication are established. This, however, is difficult to realise due to lack of working space within most health centres. A few APPs mention that working from one's own physiotherapy practice is attractive, as this increases the referral of patients for physiotherapy treatment, and therefore one's income. GPs indicate that working from one's own physiotherapy practice is not desirable, as independence of care and the role of APPs come into question. All participants see the added value of scaling up the team as this 
ensures continuity, independence and quality of care. All GPs indicate that they struggle with referring a sufficient number of patients, and which APP they should be contracting. A few APPs mention that it is difficult to scale up due to an insufficient number of trained APPs in their work area, and competitive attitude of other APPs.

I think that in our case she [APP] should actually work for several practices, because one practice - even though I have a large practice - one should have more opportunities available. You always have people who think, I'd rather go to the GP because then I'll see the doctor again, too. Or imagine, you have already been through a lot with a patient and then the patient prefers the GP. Not that it is necessarily better in terms of content, but because the GP is a trusted figure. [GP 3]

Establishment of proper reimbursement is crucial

All APPs and GPs indicate that the lack of an appropriate financing structure is a major barrier for both APPs, GPs, and patients. Although reimbursement is possible through the health insurer's innovation fund, GPs are not able or willing to utilize this. As patients are used to GP care being reimbursed from public health insurance, GPs will not only have to convince patients of the added value of an APP over a physiotherapist, but also inform them about additional costs. Some GPs indicate that they perceive this restricted accessibility of care due to a patient's financial position as unpleasant or unethical. Some APPs indicate that with current reimbursement APP is a competitor for physiotherapists which negatively affects their cooperation.

GPS were not really keen on using funds from the innovation fund of the health insurers for this purpose. Many GPs had also just made additional investments in physician's assistants. So that was an issue. Also, because we have another group of GPs here, some of whom think that extended scope is unnecessary. [APP 10]

\section{Positioning of APP is still unclear}

APP professional profile requires clarification

The APP competency profile developed by the Dutch professional association for APP is unknown to many APPs and leaves room for differentiation in the function of APP. All individual APPs have different views on competencies, end terms, tasks, patient population, and position in the care pathway. Some APPs indicate that this flexibility in the profile leads to ambiguity and confusion among GPs and patients. APPs and GPs have no consensus yet on the establishment of employment of APPs at the GP practice, and APPs working according to GP professional standards.

Initially that wouldn't matter to me. I think that we should say that, as a goal, it will eventually be fully under APP own authority. Certainly, to get the GPs on board I think that you must first do this under the GP's authority, until they themselves conclude, no, you can do this on your own just fine, and I don't need to be behind this, like some version of extension of care. So, I think that this must be introduced step by step. In particular if you also notice that they [GPs] are going to get up in arms, then you should introduce that very slowly. And prove yourself first. You must. [APP 6]

Page $11 / 20$ 
Almost all APPs missed support from the professional association when starting an APP practice. A platform to fall back on and more guidance, such as a concrete plan of action, standard documentation and advice on communicating with GPs were needed but not available. Virtually all APPs feel that the professional association is not sufficiently visible to the various stakeholders, and developments within the professional association take a long time. All APPs indicate that implementation of APP would benefit from a decisive board that is actively engaged in creating support among stakeholders. Lack of direction from the professional association leads to many individual initiatives, loss of control over this growing profession, and differences in the interpretation of the role and working method of APPs.

I understand that as well, because it is a new association and must be built from the ground up. Furthermore, it is not their main task, they also have of course their own jobs to do. But certainly, for this project, things [documentation] have been agreed upon and were to have been sent in, but this has not happened, which is a pity, because as a pioneer, you really need support. And that is not happening. Or at any rate, too little. [APP 2]

APP experience limited added value of training attended

The vast majority of the APPs interviewed said that the training contributed little to the knowledge and skills they had already acquired in their work as manual or sport physiotherapist and in their previous Master's degree courses. Some APPs indicate that, compared to other countries, the scope of the training was too limited, and practical education under the supervision of a doctor was lacking.

This is fine for a few weeks, going a bit deeper into things, but does not compare with the role they play abroad, nor the training they receive for this.... They have had a completely different training in this, and this I think, is what is keeping us from getting any further with this APP story in the Netherlands. [APP 9].

\section{Tension regarding passing on ownership of patients with musculoskeletal complaints}

No place for APP among physiotherapy yet

All APPs indicate that building a collaborative network with physiotherapists in their region costs lots of time and effort, as the concept of APP is still relatively unknown. Feelings of anxiety for losing patients and unfair competition among physiotherapists play a role in the slow acceptance of APP, despite efforts made by APPs on emphasizing that it is not their intention to treat patients themselves.

How do I notice this happening? Not proving information, not sharing patients, getting angry with you the moment you see a patient and call about it, or do a report, or have another idea. If you want to set up a project about APP care, and you go to a big player in the neighbourhood who also has a similar plan, something broader, and you say, well, let's join forces, then it's all impossible. No, it's all too sensitive, too much me, me, me... This leads to extremely unpleasant conversations. [APP 1] 
Some APPs mentioned that combining the APP care model with direct access physiotherapy results in APP being a gatekeeper, in addition to the GP. This may be used as a unique selling point to expand one's own physiotherapy practice and money making, and leads to feelings of unfair competition and resistance to APP. One APP stated that it is under discussion both in the field of work and at management level who can be an APP and who cannot. Some APPs have experienced that physiotherapist's present themselves as APP without proper training. One APP mentions that the Royal Dutch Society for Physical Therapy (KNGF) agrees that, in principle, every physiotherapist can execute the function of APP.

The other one, practice $X$, just wants to scale-up. And they also want to be a part of it [setting up an APP practice in the region], but then it's no longer about the content. The worst thing I found, was that nobody has done training in APP, but they pretend to be on top of it... I think the Society, that is the regional representative of KNGF, believes that every physiotherapist should be able to be an APP. I don't agree with him at all. Manual therapy and sport physiotherapy may think so, but the KNGF has a completely different opinion. At least in our region, the KNGF simply airs this. This is already a difficult matter. [APP 3]

Finding balance in taking over GP tasks and safeguarding core values

All GPs indicate that collaboration with APP may jeopardise patient interests, due to a restricted choice of care provider and further fragmentation of care. All APPs and GPs endorse that APP should be an independent point of care, and emphasise that APP as part of a business model of one's own physiotherapy practice should be prevented at all times. However, APPs indicate that independency is difficult to realise as APP care and physiotherapy care are provided alongside each other, due to the limited number of patients, lack of workplace at healthcare centres, and poor understanding of APP services by patients. Most APPs indicate that providing independent care still has a long way to go and may not be feasible, especially for APPs that are affiliated with large physiotherapy practices with a wide variety of in-house treatment options.

On the other hand, I discussed this [lack of independent care delivery], with fellow physios already during my training, and they all say, are you crazy, everyone works that way within primary care. And they all pass the buck to each other. So, I let it rest for a while. They're right, I think the same way, but that's partly a hypocritical remark for everyone. So, then everyone needs to put his own house in order, and then we can all be morally justified. But to be honest, because I am quite a moralist, if I let go of that, I think it is going to be a difficult issue. I agree, I totally agree, I think that's the way it should be, in the ideal world, but I think we're a long way from that. [APP 11]

All GPs mentioned that, in order to provide proper general medical care, gaining and maintaining experience with musculoskeletal complaints is essential. Some APPs and GPs indicate that not all GPs are willing to hand-over patients with musculoskeletal complaints due to personal interest in this population and/or beliefs about the content of their profession and Dutch GP core values. Two of three GPs feel that APPs still have to grow into the culture of the GP practice and have find a connection with the core values. Some APPs indicate that connecting with the GPs and relating to mutual dynamics of GPs can be difficult due to other perspectives on quality of care. 
Totally different, if you think it might be a good idea to involve a secondary care orthopaedic, then the GP says, oh, no, you mustn't, because that is seen as primary care in disguise. So, you definitely shouldn't do that! You're just not aware of all these strategically sensitive things. And you think you have a great product, and the GP thinks, how so? I don't need you at all. So how are you going to connect with them? [APP 1]

\section{Discussion}

This study explored the experiences and perceptions of APPs and GPs regarding the implementation and deployment of APP in Dutch primary care. It is difficult for APPs to carve out a place for itself in the healthcare landscape, in part because GPs do not perceive a necessity to contribute to the long journey.

In this study, four themes developed through which APPs and GPs experiences of APP deployment and implementation can be understood. The first theme showed that success of APP depends on the trust of the GP and a clearly perceived added value for the GP compared to the already existing care. The second theme made it clear that support of the GP is essential for APP, among other things to get different referral flows going. The GP also plays an important role in building the self-confidence of APPs, in creating uniformity within patient care, and in realizing working in a team under one roof. The lack of funding for APP creates concerns regarding the deployment of APP among APPs, GPs and physiotherapists. As a third theme, the professional profile of APP proved to be unclear to GPs and APPs. In the absence of a uniform way of working, everyone is still searching and there is diversification. Among APPs there is a need for better positioning, support and profiling from the professional association and for training with more depth and practical education. The fourth theme is the tension that currently still exists around the ownership of patients with musculoskeletal complaints and the competition between APPs and physiotherapists. This is compounded by the lack of adequate funding and of the ability to generate patient flow for the physical therapy practice to which an APP is affiliated. Moreover, APP seems to connect insufficiently with GP core values.

\section{Comparison with literature}

Many of the themes identified are consistent with earlier publications on APP, such as the role of trust and acceptance by doctors $[14,16]$, recognition of the added value by doctors $[14,16,17]$ and the establishment of an appropriate financing structure $[14,17]$. The current study shows that many of these factors, such as physician trust and demonstrating clear added value to stakeholders and the financing structure, have not yet been sufficiently realised to facilitate the implementation of APP. Organisational introduction and support have been described as helpful in studies of APP embedded in secondary or tertiary care $[14,15,17,18]$. Such support is lacking in the implementation of APP in the Netherlands, and an individual APP working independently in primary care will need to build a partnership without support.

A number of studies have shown that the availability of training at an appropriate level is very important [14-16]. Our study showed that, in the experience of the APPs, the current form and scope of education is not in line with the demands of the professional field and offers too little contrast with training that has already been completed and therefore lacks added value. In addition, the individual APP is currently 
responsible for organising his own practical training in the field. It is unclear to what extent this is feasible for APPs given the limited scale of most collaborations, where guidance often has to be provided by an individual GP, and gaining practical experience depends on the limited number of patients registered with this GP.

In addition, a number of studies show that a clear delineation of the role of APP and standardization of working procedures is important $[19,20,22]$. A recently conducted qualitative study on goals, roles and tasks of APPs in the Netherlands revealed that participants found it difficult to state clear goals for APPs and that there is no consensus on the positioning of APP [22]. A study on shaping interprofessional collaboration between GPs and established healthcare professionals [23] shows that collaboration does not always go well and that a shared vision and clarity regarding work structure, procedure and role distribution is important. In addition, awareness of each other's context and expectations plays a role. In the opinion of APPs and GPs, a clearly defined role and standardization of process and working methods of the APP have not yet been realized. This makes building a partnership between an APP and a GP difficult.

Among GPs, there is a need to improve the already existing collaboration with physiotherapists to ensure the increasingly complex care of patients with musculoskeletal complaints [23]. Within current Dutch primary care, about half of all GPs already have an existing collaboration with a physiotherapist [24], and a large proportion of patients with musculoskeletal complaints visit a physiotherapist via Direct Access Physiotherapy [25]. In this context, the question is whether there is a need for a new type of care provider, such as APP, or whether there is a need to revise the existing collaborations with physiotherapists, involving better communication and one-off diagnostic consultations.

In other countries, such as Australia and the United Kingdom, APP has emerged based on both demand and a sense of urgency and need among physicians $[14,16]$. Here, involved stakeholders have felt sufficient urgency to change and, in addition, physicians have endorsed the need for the use of an APP [14-16]. Within our study, a similar urgency and need among general practitioners did not emerge. This may be explained by differences in organization of healthcare systems, and good accessibility and continuity of Dutch GP care. It was also found that when the deployment of APP is not initiated by physicians, the implementation of APP is more difficult and depends on goodwill [16]. This also seems to be the case with the implementation of APP in the Netherlands.

It remains to be seen to what extent APP fits in the Dutch College of General Practitioners future vision [26] in which the GP, as the first point of contact, maintains an overview of medical care and determines, together with the patient, what care is necessary and appropriate. The Dutch General Practitioners Association has recommended that, when entering into a partnership with a new care provider, GPs must determine, before actually doing so, to what extent the core values and core tasks are to be guaranteed [27-29]. Moreover, GPs are advised to assess if the collaboration with this new care provider meets their own preferences, ambitions, and vision on GP care [27-29]. In addition, a study among patients of Dutch GPs shows that the patients' wishes regarding a healthcare provider should be considered in ever increasing collaborations with the GP practice [30]. At present, it is not feasible for APP to adequately align with key conditions that GPs want to 
see fulfilled before they are willing to change their practices, and it is unclear to what extent patients' wishes are being heeded in the implementation and deployment of APP.

The importance of connecting to core values is also highlighted in a study evaluating barriers to implementation of the Dutch General Practitioners Association treatment standards [31]. This study shows that, despite the positive attitude of GPs towards the implementation of these standards, GPs only follow the standards when they are in line with the core value of patient-centred care. This makes it clear that, even with an improved positioning of APP, connecting to the core value of person-centred care is decisive to successfully implement the use of APP. There seems to be a lack of vision under what conditions this can be met, which makes the individual APP puzzle with connecting with the GP.

\section{Strengths and Limitations}

The credibility [32] of this study is a strong point. The starting point was an extensive literature review which was used to draft the interview guide. Multiple researchers collaborated on this study, and during the analysis, two researchers coded independently of each other, and subsequently the codes and themes were extensively coordinated and discussed within the research team. In addition, the full scope of the use and implementation of APP was examined by using the concepts of the constellation approach as sensitising concepts in developing the interview guide. Also, all participants were sent a member check after the interview and their responses were included in the analysis. The conformability [32] of the results is compelling as a large team with different backgrounds worked on the study. Moreover, there has also been a good audit trial, in which the selection process around the analysis was recorded and explicit attention was paid to own views and thought processes, especially given the involvement of one individual researcher (SP) in an observational study on the deployment of APP. The transferability [32] of findings is unclear. Despite similar findings in the literature on implementation level, comparison with international literature is difficult given the specific Dutch context. We aimed for maximum variation in sampling. However, since we do not know the characteristics of the entire APP professional group, it is unknown if we succeeded. In addition, the perception of GPs regarding the implementation of APP is still limited because only three GPs participated, and results regarding the perceptions of GPs are partly based on perceptions of the APP on the GP. There may be shortcomings in the dependability [32] of the findings. Although data saturation was achieved and flexible analysis took place, data collection and data analysis were not a fully iterative process. In addition, there is a possibility that some participants may have been less free to express themselves within the study, as they might have felt that they, despite that their interview was anonymised, still could be recognized among colleagues and stakeholders based on their specific characteristics.

\section{Conclusion}

Results of this study show that the implementation of an APP model of care is challenging. The deployment of APP does not sufficiently align with the core values of GPs, and GPs seem reluctant to hand-over some control over patient care to APPs. APP does not appear to have ownership of the implementation, given its strong dependence on the practice, values and needs of the GP.

\section{List Of Abbrevations}


APP Advanced Practitioner in Physiotherapy

GP General Practitioner

KNGF Koninklijk Nederlands Genootschap voor Fysiotherapie (Royal Dutch Society for Physical Therapy)

\section{Declarations}

Ethics approval and consent to participate: All participants have given written informed consent before participating in this study. Ethical approval was obtained from the Medical Ethics Committee of the VU University Medical Centre in Amsterdam; reference number 2020.17. Reporting was in accordance with the COREQ guidelines.

Consent for publication: Not applicable

Availability of data and materials: The data used and /or analysed during the current study are available from the corresponding author on reasonable request.

Competing interests: The authors declare that they have no competing interests.

Funding: The authors received financial support for the research, authorship, and publication from the Dutch Association for Manual Therapy (Nederlandse Vereniging voor Manuele Therapie). The Dutch Association for Manual Therapy had no role in the design of the study or collection, analysis, and interpretation of data or in writing the manuscript.

Authors' contributions: Study conception: AP, RO, MvT. Design and protocol writing: SP, AP, RO, MvT, ER. Data collection SP. Data Analysis and interpretation: SP, LB, MD. Manuscript writing: SP. Revision Manuscript: MD, ER, LB, MvT, RO, and AP. All authors read and approved the final manuscript.

Acknowledgements: We would like to thank Sidney and Tammy Rubinstein for translating the quotes.

Authors' information: A team of researchers from different backgrounds participated in this study, namely SP (physiotherapist, clinical epidemiologist, and involved in observational study on Advanced Practice Physiotherapists), MD (Health scientist and Methodologist), ER (GP Policy and Management), LB (Health scientist and unfamiliar with Advanced Practice Physiotherapists), AP (Involved in observational study on Advanced Practice Physiotherapists, involved in training institute that organises Advanced Practice Physiotherapists training and initial advisor to Dutch professional association for Advanced Practice Physiotherapists), RO (physiotherapist, epidemiologist and involved in observational study on Advanced Practice Physiotherapists) and MvT (epidemiologist, experience with qualitative research and involved in an observational study on Advanced Practice Physiotherapists).

\section{References}

1. Garson A Jr, Levin SA. Ten 10-year trends for the future of healthcare: implications for academic health centers. Ochsner J. 2001;3:10-15. 
2. Van der Horst H, Bindels P, Assendelft P, Berger M, Muris J, Numans M, Van Weert H, De Wit N. Hoogste tijd voor minder patiënten per huisarts. Huisarts Wet. 2018; doi:10.1007/s12445-018-0056-9.

3. Schäfer WLA, van den Berg MJ, Groenewegen PP. De werkbelasting van huisartsen in internationaal perspectief. Huisarts Wet. 2016;59:94-101.

4. Laurant M, van der Biezen M, Wijers N, Watananirun K, Kontopantelis E, van Vught AJAH. Nurses as substitutes for doctors in primary care. Cochrane Database of Systematic Reviews. 2018; doi:10.1002/14651858.CD001271.pub3.

5. Bennett M, Walters K, Drennan V, Buszewicz M. Structured pro-active care for chronic depression by practice nurses in primary care: a qualitative evaluation. PLoS One. 2013; doi:10.1371/journal.pone.0075810.

6. Baker E, Gwernan-Jones R, Britten N, Cox M, McCabe C, Retzer A, Gill L, et al. Refining a model of collaborative care for people with a diagnosis of bipolar, schizophrenia or other psychoses in England: a qualitative formative evaluation. BMC Psychiatry. 2019; doi:10.1186/s12888-018-1997-z.

7. Halcomb EJ, McInnes S, Patterson C, Moxham L. Nurse-delivered interventions for mental health in primary care: a systematic review of randomized controlled trials. Fam Pract. 2019;doi:10.1093/fampra/cmy101.

8. Tawiah AK, Desmeules F, Wieler M, Finucane L, Lewis J, Woodhouse LJ, et al. Advanced Practice in Physiotherapy: A Global Survey. Physiotherapy. 2021;doi:https://doi.org/10.1016/j.physio.2021.01.001.

9. Vedanayagam M, Buzak M, Reid D, Saywell, N. Advanced practice physiotherapists are effective in the management of musculoskeletal disorders: a systematic review of systematic reviews. Physiotherapy. 2021;doi.org/10.1016/j.physio.2021.08.005.

10. Kersten P, Kath McPherson K, Lattimer V, George S, Breton A, Ellis B. Physiotherapy extended scope of practice - who is doing what and why? Physiotherapy. 2007;doi.org/10.1016/j.physio.2007.02.007.

11. Lafrance S, Demont A, Thavorn K, Fernandes J, Santaguida C, Desmeules F. Economic evaluation of advanced practice physiotherapy models of care: a systematic review with meta-analyses. BMC health services research. 2021;doi:10.1186/s12913-021-07221-6.

12. Gérvas J, Pérez Fernández M. Western European best practice in primary healthcare. Eur J Gen Pract. 2006;doi: 10.1080/13814780600757187.

13. Groenewegen P, Schäfer, W, Schellevis F, Boersma W. Kernwaarden van Nederlandse huisartsen in internationaal perspectief. Huisarts Wet. 2020;doi:10.1007/s12445-020-0760-0.

14. Shaw BR, Heywood SE, Page CJ, Phan UM, Harding PA, Walter K, et al. Advanced musculoskeletal physiotherapy: Barriers and enablers to multi-site implementation. Musculoskeletal Care. 2018;doi:10.1002/msc.1358.

15. Tawiah AK, Borthwick A, Woodhouse L. Advanced Physiotherapy Practice: A qualitative study on the potential challenges and barriers to implementation in Ghana. Physiother Theory Pract. 2020;doi:10.1080/09593985.2018.1484535.

16. Dawson LJ, Ghazi F. The experience of physiotherapy extended scope practitioners in orthopaedic outpatient clinics. Physiotherapy. 2004;doi:10.1016/j.physio.2004.06.001. 
17. Morris J, Grimmer K, Gilmore L, Perera C, Waddington G, Kyle G, et al. Principles to guide sustainable implementation of extended-scope-of-practice physiotherapy workforce redesign initiatives in Australia: stakeholder perspectives, barriers, supports, and incentives. J Multidiscip Healthc. 2014;doi:10.2147/JMDH.S59473.

18. Jones A, Powell T, Watkins D, et al. Realising their potential? Exploring interprofessional perceptions and potential of the advanced practitioner role: a qualitative analysis. BMJ Open 2015;doi:10.1136/bmjopen-2015-009740.

19. van Raak R. The transition (management) perspective on long-term changes in healthcare. In: Broerse JEW, Bunders - Aelen JFG, editors. Transitions in Health Systems: Dealing with persistent problems. Amsterdam: VU University Press; 2010. p. 49-86.

20. Creswell JW. Research design: Qualitative, quantitative, and mixed methods approaches. 2nd ed. Thousand Oaks: Sage; 2007.

21. Braun V, Clarke, V. Using thematic analysis in psychology. Qualitative Research in Psychology. 2006;doi:10.1191/1478088706qp063oa.

22. Bastiaens F, Barten DJ, Veenhof C. Identifying goals, roles and tasks of extended scope physiotherapy in Dutch primary care- an exploratory, qualitative multi-step study. BMC Health Serv Res. 2021:doi:10.1186/s12913-020-05986-w.

23. Van Dongen JJJ, Van Bokhoven MA, Goossens WNM, Daniëls R, Van der Weijden T, Beurskens A. Steeds complexere zorg vraagt om teamwerk. Huisarts Wet. 2019;doi:10.1007/s12445-019-0305-6.

24. Zaat J. De kern van het vak. Huisarts en netwerk. Huisarts Wet. 2018;doi:10.1007/s12445-018-0390-y.

25. Netherlands Institute for Health Services Research. Zorg door de Fysiotherapeut; Nivel Zorgregistraties Eerste Lijn, Jaarcijfers 2019 en trendcijfers 2016-2019. https://www.nivel.nl/nl/nivel-zorgregistratieseerste-lijn/cijfers-zorgverlening-fysiotherapeuten. Accessed 30 Nov 2021.

26. Dutch College of General Practitioners. NHG toekomstvisie 2012-2022. https://www.nhg.org/sites/default/files/content/nhg_org/uploads/nhg-toekomstvisie-kernbinnenwerk.pdf. Accessed 30 Nov 2021.

27. Bijma B. Wat is uw ideale team. In: De dokter. Dutch General Practitioners Association. 2020. https://www.lhv.nl/actueel/de-dokter/de-dokter-oktober-2020/wat-is-uw-ideale-team/.

28. Accessed 30 Nov 2021.

29. Lambregtse C. Nieuwe initiatieven in de huisartsenzorg: bedreiging of kans? Dutch General Practitioners Association. 2021. https://www.lhv.nl/wp-content/uploads/2021/11/DD2106_08-13_Aanbieders.pdf. Accessed 30 Nov 2021.

30. Dutch General Practitioners Association. LHV-afwegingsinstrument Nieuwe aanbieders in de huisartsenzorg. https://www.lhv.nl/product/lhv-afwegingsinstrument-nieuwe-aanbieders-in-dehuisartsenzorg/. Accessed 30 Nov 2021.

31. Jabaaij L, Schers HJ, Van Essen GA, Goudswaard AN, Schellevis FG. Every time the same GP? A study of patients' wishes and appreciation. Huisarts Wet. 2006;doi:10.1007/BF03084995.

32. Lugtenberg M, Zegers-van Schaik J, Wesert G, Bergers J. Why don't physicians adhere to guideline recommendations in practice? An analysis of barriers among Dutch general practitioners. 
Implementation Science 2009;doi: doi:10.1186/1748-5908-4-54.

33. Frambach JM, van der Vleuten CP, Durning SJ. AM last page. Quality criteria in qualitative and quantitative research. Acad Med. 2013;doi:10.1097/ACM.0b013e31828abf7f.

\section{Supplementary Files}

This is a list of supplementary files associated with this preprint. Click to download.

- AdditionalFile1Pellekoorenetal.docx 